XLVIth Zakopane School of Physics, International Symposium Breaking Frontiers, Zakopane, Poland, May 16-21, 2011

\title{
Chemical Composition of Atherosclerotic Plaques of apoE/LDLR-Double Knockout Mice by Synchrotron Radiation FTIR Microspectroscopy
}

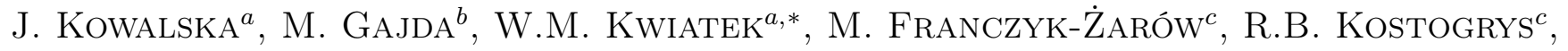
S. ChŁOPICKI ${ }^{d}$, C. SANDT ${ }^{e}$ AND P. Dumas ${ }^{e}$

${ }^{a}$ The Henryk Niewodniczański Institute of Nuclear Physics, Polish Academy of Sciences, Kraków, Poland

${ }^{b}$ Department of Histology, Jagiellonian University Medical College, Kraków, Poland

${ }^{c}$ Faculty of Food Technology, Department of Human Nutrition, Agricultural University, Kraków, Poland

${ }^{d}$ Department of Experimental Pharmacology, Jagiellonian University Medical College, Kraków, Poland

${ }^{e}$ French Synchrotron Facility SOLEIL, Gif-sur-Yvette, Cedex, France

\begin{abstract}
Atherosclerosis is a multietiological inflammatory disease of large and medium-sized arteries of increasing incidence in westernized countries. The aim of this study was to identify the biochemical changes during the progression of atherosclerosis by synchrotron radiation Fourier transform infrared microspectroscopy in atheromas of apoE/LDLR ${ }^{-/-}$mice fed egg-rich diet supplemented or not with angiotensin converting enzyme inhibitor perindopril. Synchrotron radiation Fourier transform infrared microspectroscopy technique was used to obtain information at high spatial resolution about the distribution of proteins $(\mathrm{C}-\mathrm{N}, \mathrm{N}-\mathrm{H}, \mathrm{CO}$ for amide I and amide II bands), lipids $\left(\mathrm{CH}_{2}, \mathrm{CH}_{3}\right.$ bands) as well as mineral deposits (calcium carbonates and phosphates). Total contents of lipids and proteins were found to be significantly lower in animals treated with the diet and perindopril. An increase in saturation level of lipids was observed in animals fed with egg-rich diet when compared to the normal diet and perindopril treatment, which did not inhibit this effect. Moreover, a significant change in the secondary structure of proteins (ratio between absorption bands $1634 \mathrm{~cm}^{-1} / 1656 \mathrm{~cm}^{-1}$ attributed to $\beta$-type and $\alpha$-type, respectively) was observed in both experimental groups in comparison with the control. Principal component analysis was used to analyse the recorded spectra. It has revealed that higher content of phosphates (wavenumber range $950-1020 \mathrm{~cm}^{-1}$ ) was observed between egg-rich diet fed animals and the control group.
\end{abstract}

PACS: 87.19.xr, 87.64.km, 87.64.-t

\section{Introduction}

Atherosclerosis is currently the largest cause of mortality in westernized human populations and it has been a subject of many experimental studies and clinical trials dedicated to its pathomechanism and treatment. Recent hypothesis explaining the etiopathology of atherosclerosis involves endothelial dysfunction, deposition and oxidation of low density lipoproteins (LDL), migration of inflammatory cells (mostly macrophages) and smooth muscle cells, as well as matrix remodeling [1].

After several attempts, a reliable animal model of atherosclerosis was identified. Gene-targeted, apoliprotein E and LDL receptor-double knockout (apoE/LDLR ${ }^{-/-}$) mice display serious hyperlipidemia and advanced atherosclerotic lesions. Biological effects of new antiatherosclerotic drugs and diets have been studied on this model $[2,3]$. Moreover, X-ray based synchrotron radiation microprobes were successfully applied to characterize elemental composition of atherosclerotic lesions in apoE $/ \mathrm{LDLR}^{-/-}$mice [4].

Nutritional habits strongly influence the development

* corresponding author; e-mail: wojciech.kwiatek@ifj.edu.pl of atherosclerosis. Diets based on fat-rich products are known as risk factors of atherosclerosis [5]. The presence of various lipids and the content of their peroxides were shown to correlate with the progress of the disease in human arteries [6, 7]. Proatherosclerotic effect is mostly caused by exogenous cholesterol and the role of its oxidation was emphasized in egg-rich diets [8]. Pharmacological treatment may inhibit development of atheromas caused by dietary habits. Perindopril, an angiotensin converting enzyme (ACE) inhibitor was reported to reduce atherosclerosis in mice and in humans $[9,10]$. Recently, changes in concentrations of selected trace elements (including $\mathrm{P}, \mathrm{Ca}, \mathrm{Fe}, \mathrm{Cu}$ and $\mathrm{Zn}$ ) in atherosclerotic plaques of apoE/LDLR ${ }^{-/-}$mice fed egg-rich diet supplemented with perindopril were studied using synchrotron radiation induced X-ray emission microspectroscopy ( $\mu$-SRIXE) [11].

Other spectroscopic methods were also applied to the studies of atherosclerosis. Synchrotron radiation Fourier transform infrared microspectroscopy (SR- $\mu$ FTIR) was used to determine the two-dimensional distribution of functional groups of biomolecules such as lipids, proteins, and minerals. The use of synchrotron radiation as infrared light source allows to obtain the molecular information on biological samples with a very high signal to 
noise ratio and spatial resolution (about $12 \mu \mathrm{m}$ in size). Moreover, the high brightness and flux of this radiation allow to be measured in a non-destructive way on small amounts of samples like tissue sections [12, 13].

The current study is a continuation of our previous research demonstrating physicochemical composition of atherosclerotic plaques of gene-targeted mice. The aim of this study was to show differences in the distribution and concentration of lipids, proteins and calcium compounds in atheromas of atherosclerotic lesions of apoE/LDLR ${ }^{-/}$mice fed egg-rich diet supplemented or not with perindopril applying SR- $\mu$ FTIR spectroscopy [11].

\section{Material and methods}

\subsection{Animals and treatment}

Fifteen female apoE $\mathrm{E}^{-/-} / \mathrm{LDLR}^{-/-}$mice were obtained from Taconic (Ejby, Denmark) and kept in $12 \mathrm{~h} /$ $12 \mathrm{~h}$ light/dark cycle with an unlimited access to water in room temperature $\left(22.5 \pm 0.5^{\circ} \mathrm{C}\right)$ and $50 \pm 5 \%$ humidity. Up to the age of 4 months the animals were fed with a commercial, cholesterol-free diet and then they were randomly assigned to one of three experimental groups fed for the following 2 months: (i) AIN-93G cholesterol-free normal diet ( $n=5$, control group, CHOW), (ii) AIN-93G diet supplemented with 5\% egg-yolk lyophilisate ( $n=5, \mathrm{LYOPH}$ ) and (iii) AIN-93G diet supplemented with $5 \%$ egg-yolk lyophilisate and perindopril $(2 \mathrm{mg} / \mathrm{kg}$ b.w.; $n=5$, LYOPH/PERIND).

National and international principles of laboratory animal care conforming to the Declaration of Helsinki guidelines were followed and all procedures were approved by Jagiellonian University Animal Experimentation Ethics Committee.

\subsection{Specimen preparation}

Six month old mice were anaesthetized by intraperitoneal injection of sodium thiopental $(100 \mathrm{mg} / \mathrm{kg}$ b.w. Morbital, Biowet, Puławy, Poland). Hearts with ascending aortas were excised, rinsed with phosphate-buffered saline (PBS), embedded in OCT compound (Jung, Nussloch, Germany) and snap frozen. Serial $10 \mu \mathrm{m}$ thick sections of the aortic root were cut on cryostat and mounted on $3.5 \mu \mathrm{m}$ thick Mylar foil (Oxford Instruments, Espoo, Finland).

\subsection{FTIR measurements}

The SR- $\mu$ FTIR measurements were carried out at the SMIS beamline at SOLEIL synchrotron facility (Gif-sur-Yvette, Cedex, France). The beamline was equipped with a Thermo Nicolet Nexus 5700 spectrometer coupled with a Continuum XL IR microscope and a $50 \mu \mathrm{m}$ $\mathrm{MCT} / \mathrm{A}$ detector. Two types of measurements were performed: high spatial resolution 2D imaging of lesional areas of the aortic root with surrounding cardiac muscle and single point spectral analyses from histologically defined areas rich in lipids and macrophages (atheromas). All the spectra were obtained in transmission mode in wavenumber range from $650 \mathrm{~cm}^{-1}$ to $4000 \mathrm{~cm}^{-1}$ with a spectral resolution of $4 \mathrm{~cm}^{-1}$. The samples were probed using full width at half maximum (FWHM) of the beam size $12 \mu \mathrm{m}$ and the spectra were recorded with the repetition of 256 scans. Acquired data were preprocessed with OMNIC software ver. 8.0 (Thermo), corrected for Mie scattering effect in Matlab ver. 7.5 software applying Bassan et al. algorithm [14] and normalized using vector normalization.

\subsection{Statistical analysis}

For comparison of the contents of specific compounds between studied groups of animals, the intensities of main bands or sum areas of band ranges were used. Differences between groups were confirmed statistically significant with $p<0.05$ applying non-parametric Mann-Whitney U-test (Statistica 8.0).

\section{Results and discussion}

\subsection{Chemical analysis}

From all group point analyses final FTIR spectra recorded in atheromas from all studied groups were calculated and average spectrum for control group is presented in Fig. 1. The assignments of the various infrared bands are reported in Table $\mathrm{I}$.

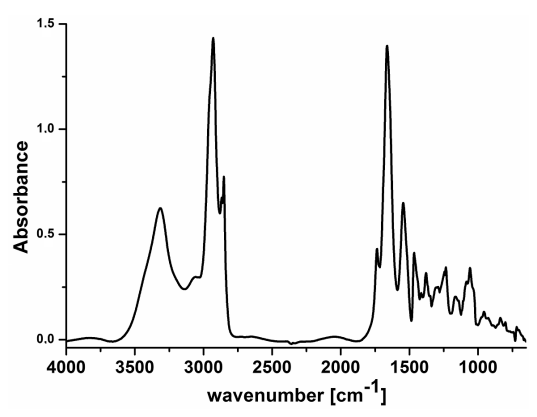

Fig. 1. Averaged spectrum from point measurements in atheromas of control group. Characteristic peaks for analyzed molecules are detailed in Table I.

The bands position was determined based on the second derivative spectrum. Then the bands were fitted with Gaussian curve in order to obtain the integrated peak area of all components. Higher total content of lipids (sum of band ranges $2929 \mathrm{~cm}^{-1}, 2961 \mathrm{~cm}^{-1}$, $1739 \mathrm{~cm}^{-1}, 1466 \mathrm{~cm}^{-1}, 1378 \mathrm{~cm}^{-1}$ ) [16] was observed in atheromas of animals fed egg-rich diet comparing to control animals, although the difference was not statistically significant (Table II). Total lipid concentration was lower in perindopril-treated animals in comparison to other groups (Table II, IIIa). Differences in total protein concentrations (sum of band ranges $3300 \mathrm{~cm}^{-1}$, 3090-3068 cm $\mathrm{cm}^{-1}, 1656 \mathrm{~cm}^{-1}, 1634 \mathrm{~cm}^{-1}, 1547 \mathrm{~cm}^{-1}$ ) [17] were also observed between analyzed groups showing much lower protein content in perindopril-treated animals comparing to other groups (Table II, IIIb). 
TABLE I

Assignments of IR bands or band ranges for specific bonds and chemical compounds from Ref. [15] and from our studies.

\begin{tabular}{|c|c|c|c|}
\hline $\begin{array}{c}\text { wavenumber } \\
{\left[\mathrm{cm}^{-1}\right][18]}\end{array}$ & $\begin{array}{c}\text { Our results } \\
{\left[\mathrm{cm}^{-1}\right]}\end{array}$ & Assignment & Source \\
\hline$\approx 3300$ & 3308 & $\mathrm{~N}-\mathrm{H} \operatorname{str}($ amide $\mathrm{A})$ & proteins \\
\hline $3100-3030$ & 3090-3068 & $\mathrm{N}-\mathrm{H}$ str (amide $\mathrm{B}$ ) & proteins \\
\hline$\approx 2960$ & 2961 & $\mathrm{CH}_{3}$ asym str & lipids \\
\hline$\approx 2930$ & 2929 & $\mathrm{CH}_{2}$ asym str & lipids \\
\hline$\approx 2870$ & 2869 & $\mathrm{CH}_{3}$ sym str & lipids \\
\hline$\approx 2850$ & 2852 & $\mathrm{CH}_{2}$ sym str & lipids \\
\hline $1750-1720$ & 1739 & $\mathrm{C}=\mathrm{O}$ str & Lipids \\
\hline$\approx 1660$ & $1664-1656$ & $\mathrm{CO}$ str, CN str, NH ben vib (amide I) & proteins \\
\hline$\approx 1630$ & 1634 & CO str (amide I) & proteins \\
\hline$\approx 1545$ & 1547 & NH bend vib, CN str (amide II) & proteins \\
\hline$\approx 1460$ & 1466 & $\mathrm{CH}_{3}$ asym bend & lipids \\
\hline$\approx 1440$ & 1438 & $\mathrm{CH}_{3}$ sym bend & lipids \\
\hline$\approx 1415$ & 1413 & $\mathrm{Ca}-\mathrm{O}$ & calcium carbonate \\
\hline$\approx 1380$ & 1378 & $\mathrm{CH}_{3}$ sym bend & lipids \\
\hline$\approx 1345$ & 1347 & $\mathrm{CO}_{3}^{2-}$ & calcium carbonate \\
\hline$\approx 1315$ & 1314 & $\mathrm{C}-\mathrm{H}$ skeletal vibrations & proteins \\
\hline $1230-1300$ & 1293 & amide III & proteins \\
\hline$\approx 1240$ & 1239 & $\mathrm{P}=\mathrm{O}$ asym $\mathrm{str}$ & nucleic acids \\
\hline$\approx 1170$ & 1168 & $\mathrm{COC}$ & lipids, polysaccharides \\
\hline$\approx 1140$ & 1139 & $\mathrm{C}-\mathrm{N}$ str & proteins \\
\hline$\approx 1080$ & 1082 & $\mathrm{P}=\mathrm{O}$ sym $\mathrm{str}$ & nucleic acids \\
\hline$\approx 1060$ & 1058 & $\mathrm{C}=\mathrm{O}$ str & lipids \\
\hline$\approx 1035$ & 1033 & $\mathrm{C}-\mathrm{H}$ str & lipids \\
\hline$\approx 980$ & 978 & $\mathrm{PO}_{4}^{3-}$ & calcium phosphate \\
\hline$\approx 960$ & 956 & $\mathrm{C}-\mathrm{CH}_{3}$ & lipids \\
\hline$\approx 930$ & 923 & $\mathrm{PO}_{4}^{3-}$ & calcium phosphate \\
\hline$\approx 880$ & 873 & $\mathrm{CO}_{3}^{2-}$ & calcium carbonate \\
\hline$\approx 860$ & 858 & $\mathrm{C}-\mathrm{S}$ & proteins \\
\hline$\approx 840$ & 839 & $\mathrm{CO}_{3}^{2-}$ & calcium carbonate \\
\hline$\approx 770$ & 766 & $\mathrm{P}-\mathrm{O}-\mathrm{P}$ & calcium phosphate \\
\hline$\approx 745$ & 743 & $\mathrm{CO}_{3}^{2-}$ & calcium carbonate \\
\hline$\approx 715$ & 718 & $\mathrm{Ca}-\mathrm{O}$ asym bend & calcium carbonate \\
\hline
\end{tabular}

Saturation level of lipids calculated as ratio of intensities between bands $2929 \mathrm{~cm}^{-1}$ and $2961 \mathrm{~cm}^{-1}$ in groups of animals treated with egg-rich diet was about twice higher than in control group and the treatment with perindopril did not decrease this level (Table IV, Va).

The content of proteins with secondary $\beta$-sheet to the content of $\alpha$-helix structure $\left(1634 \mathrm{~cm}^{-1} / 1656 \mathrm{~cm}^{-1}\right)$ varied between experimental groups and the control group (Table IV, Vb). Decrease in proportion between concentrations of proteins with $\beta$-type and $\alpha$-type structure (ratio between absorption bands $1634 \mathrm{~cm}^{-1} / 1656 \mathrm{~cm}^{-1}$ ) was seen in both experimental groups as comparing to the control.
Since numerous overlapping bands may originate from calcium carbonates and calcium phosphates (see Table I) which are the main constituents of mineral deposits in aortic wall, a statistical analysis of the spectra was performed. Principal component analysis (PCA) was used in the region from $710 \mathrm{~cm}^{-1}$ to $1420 \mathrm{~cm}^{-1}$ to reduce the matrix of spectral data in which each spectrum is represented by a large number of variables (wavenumbers) to smaller number (PCs) which describes the variance [18].

The application of PCA indicated that just only three principal components express over $96.9 \%$ of the variance in the analyzed data set (Fig. 2). The first principal component represents $89.7 \%$ of the variance of the complete 


\section{TABLE II}

Comparison of total lipid and total protein content in studied groups (median \pm SD calculated as sum of integrated intensity of adequate bands mentioned in text).

\begin{tabular}{c|c|c|c}
\hline \hline Group & CHOW & LYOPH & LYOPH/PERIND \\
\hline Lipids & $0.029 \pm 0.007$ & $0.032 \pm 0.007$ & $0.020 \pm 0.005$ \\
Proteins & $0.033 \pm 0.009$ & $0.029 \pm 0.009$ & $0.021 \pm 0.004$
\end{tabular}

TABLE III

Differences in total lipid and total protein content between studied groups ( $p$-values of U-test, significant differences marked with asterisks).

\begin{tabular}{l|c|c|c}
\hline \hline a) Lipids & CHOW & LYOPH & LYOPH/PERIND \\
\hline CHOW & & & \\
LYOPH & 0.20 & & \\
LYOPH/PERIND & $0.005^{*}$ & $0.001^{*}$ & \\
\hline b) Proteins & CHOW & LYOPH & LYOPH/PERIND \\
\hline CHOW & & & \\
LYOPH & 0.16 & & \\
LYOPH/PERIND & $0.0001^{*}$ & $0.02^{*}$ &
\end{tabular}

TABLE IV

Comparison of saturation levels of lipids $\left(2929 \mathrm{~cm}^{-1} / 2961 \mathrm{~cm}^{-1}\right)$ and contents of $\alpha$-helix and $\beta$-sheet $\left(1634 \mathrm{~cm}^{-1} / 1656 \mathrm{~cm}^{-1}\right)$ proteins in studied groups (median \pm SD calculated as integrated intensity ratio).

\begin{tabular}{l|c|c|c}
\hline \hline Group & CHOW & LYOPH & LYOPH/PERIND \\
\hline $2929 / 2961$ & $0.59 \pm 0.04$ & $1.26 \pm 0.05$ & $1.21 \pm 0.02$ \\
$1634 / 1656$ & $1.21 \pm 0.24$ & $0.71 \pm 0.09$ & $0.81 \pm 0.03$
\end{tabular}

TABLE V

Differences in saturation levels of lipids, contents of $\alpha$-helix and $\beta$-sheet proteins between studied groups ( $p$-values of U-test, significant differences marked with asterisks).

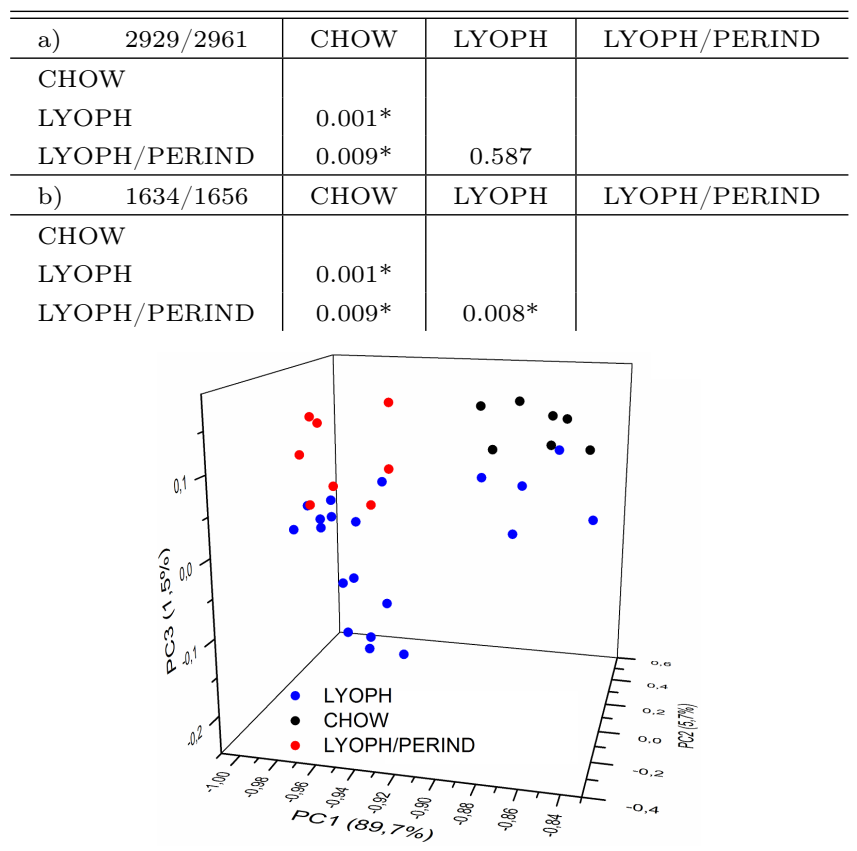

Fig. 2. 3D plot of three principal components after PCA on infrared spectra in region $710 \mathrm{~cm}^{-1}$ to $1420 \mathrm{~cm}^{-1}$ for studied groups. The variances described by those PCs are marked by percentage labels on each axis.
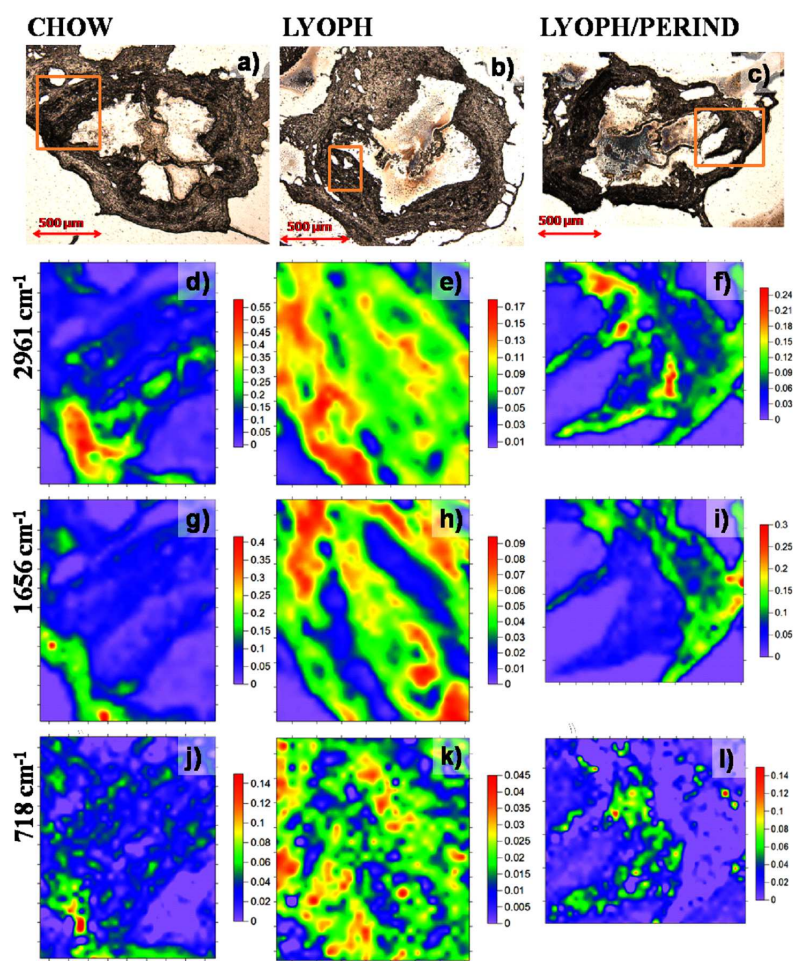

Fig. 3. Microscopic images (a)-(c) and 2D maps of distributions of lipids $(\mathrm{d})-(\mathrm{f})$, proteins $(\mathrm{g})-(\mathrm{i})$ and calcium minerals $(\mathrm{j})-(\mathrm{l})$ in studied groups.

data set and has a loading profile dominated by features of $950-1020 \mathrm{~cm}^{-1}$ and $1320-1350 \mathrm{~cm}^{-1}$. Moreover, there is a quite clear separation between CHOW and LYOPH/ PERIND group, which applies a similarity between the spectra for these groups. These groups spread out for the values of PC1 and PC2 factor but have a similar level for PC3 values. The LYOPH group has a tendency towards LYOPH/PERIND and CHOW group in case of the values of PC1 factor but show lower values for PC3 factor.

Analysis of intensities of the absorbances from ranges 950-1020 $\mathrm{cm}^{-1}$ (corresponding to phosphates) and 1320$1350 \mathrm{~cm}^{-1}$ (corresponding to carbonates) showed only statistical difference in the range $950-1020 \mathrm{~cm}^{-1}$ between CHOW and LYOPH groups (Tables VI, VII).

TABLE VI

Comparison of calcium mineral levels (phosphates and carbonates) in studied groups (median \pm SD calculated as integrated intensity).

\begin{tabular}{c|c|c|c}
\hline \hline Group & CHOW & LYOPH & LYOPH/PERIND \\
\hline $957 \mathrm{~cm}^{-1}$ & $0.014 \pm 0.002$ & $0.029 \pm 0.007$ & $0.024 \pm 0.005$ \\
$1347 \mathrm{~cm}^{-1}$ & $0.027 \pm 0.008$ & $0.024 \pm 0.005$ & $0.026 \pm 0.007$
\end{tabular}

\subsection{Chemical distribution}

2D maps of band $2961 \mathrm{~cm}^{-1}$ (Fig. 3d-f) present the distribution of lipids. Lipids were observed mainly in atheromas (central regions of atherosclerotic lesions) and their content was much higher in LYOPH group. In LYOPH group they occupied almost entire thickness of 
TABLE VII

Differences in calcium mineral levels between studied groups ( $p$-values of U-test, significant differences marked with asterisks).

\begin{tabular}{l|c|c|c}
\hline \hline a) 957-1020 $\mathrm{cm}^{-1}$ & CHOW & LYOPH & LYOPH/PERIND \\
\hline CHOW & & & \\
LYOPH & $0.0002^{*}$ & & \\
LYOPH/PERIND & $0.05^{*}$ & 0.11 & \\
\hline b) 1347-1350 cm & CHOW & LYOPH & LYOPH/PERIND \\
\hline CHOW & & & \\
LYOPH & 0.6 & & \\
LYOPH/PERIND & 1.0 & 0.8 &
\end{tabular}

the lesion while in other groups they were confined to more limited areas.

Proteins as visualized by the band around $1660 \mathrm{~cm}^{-1}$ (Fig. 3g-i) were distributed across entire lesions. However, high content of proteins was frequently seen in the periphery of the vessel reflecting location of vascular media and close to the lumen marking location of neointimal smooth muscle cells and collagen fibers (fibrous sheath).

Absorption bands that detect calcium compounds including wavenumbers $718 \mathrm{~cm}^{-1}, 957 \mathrm{~cm}^{-1}$, and $1347 \mathrm{~cm}^{-1}$ corresponding to the vibrations of $\mathrm{Ca}-\mathrm{O}$, $\mathrm{PO}_{4}^{3-}$, and $\mathrm{CO}_{3}^{2-}$, respectively, were used for visualization of mineral deposits. All the bands showed very similar distribution. Minerals were presented as distribution of band $718 \mathrm{~cm}^{-1}$ since it is common for both phosphates and carbonates (Fig. 3j-1). Calcium deposits were mostly visible in areas of strong lipid absorbance very frequently at intima/media border.

\section{Discussion}

In our previous report, histological evaluation and elemental studies showed more advanced atherosclerosis in mice fed egg-rich diet compared to chow diet fed animals. Perindopril treatment slightly reversed these effects [11]. FTIR spectroscopy allows the simultaneous acquisitions of many spectra of a sample, each containing the chemical markers (absorption bands related to vibrations of particular chemical bonds) of compounds at specific locations in histological specimen. In the current study most emphasis was placed to evaluate the saturation level of lipids as well as the relative secondary structure of proteins using $\mu$-FTIR spectroscopy. Additionally, the influence of egg-rich diet and antiatherosclerotic agent on the content and distribution of biomolecules in atherosclerotic lesions was investigated.

We showed changes in lipids content and their saturation levels. These results may be interpreted as a consequence of dietary and pharmacological treatments.

Modification in secondary structure of proteins was detected in case of egg-rich diet. Ratio of the intensities of bands $1634 \mathrm{~cm}^{-1}$ and $1656 \mathrm{~cm}^{-1}$ was calculated to detect the changes in proteins. Amide I band results primarily from the protein backbone vibrations $(\mathrm{C}=\mathrm{O}$ stretching), while the amide II mainly from $\mathrm{N}-\mathrm{H}$ bending vibrations, and both are known to be sensitive to protein backbone conformation. These parameters are of lower values for egg-rich diet treated group. Such an observation indicates that this diet, as well as perindopril one, induce local changes in the secondary structure of the proteins. Changes in protein secondary structure, from $\alpha$-helix to $\beta$-sheet are often related with the shift of amide I band towards lower wavenumbers. Therefore, this parameter can be used as a marker for protein conformational changes. In this study these values decrease in case of egg-rich treatment, that indicates the shift from $\beta$-sheet structure to $\alpha$-helix. In case of perindopril treatment this parameter increases again, which can be explained as exchange of some proteins back to $\beta$-sheet [18].

The changes in lipids ratio may indicate the influence of the diet on the lipids depositions in vessels, despite no significant changes in the total lipid content in the diet treated group as compared to the control one. This parameter may also indicate the role of lipids oxidation on the progress of atherosclerosis. The perindoprilat treatment does not reduce this effect, which might imply that this drug does not influence the formation of free radicals.

Calcium minerals are a clear evidence for atherosclerotic lesions. Some studies suggest that the calcification mechanism of atherosclerosis is similar to osteogenesis [19]. Therefore, the presence of both carbonate and phosphate minerals may reasonably confirm the act of such process in the pathogenesis of atherosclerosis [20]. In this study the significantly higher concentrations of phosphates in both experimental groups comparing to the control one was observed. This effect may reflect more advanced atherosclerosis with elevated depositions of hydroxyapatite crystals in animals treated with proatherogenic egg-rich diet. Indeed, phosphates are considered as a key indicator of the progress of atherosclerosis [21]. Addition of perindopril slightly inhibited this process but the results were not statistically significant. In our previous report [11] we observed other proportions of phosphorus in studied groups (highest in CHOW and lowest in LYOPH group). However, none of these differences were statistically significant. Moreover, total concentration of the element phosphorus may not only be indicative for the presence of phosphates but also for other phosphomolecules (e.g. phospholipids).

\section{Conclusions}

In this research the SR- $\mu$ FTIR spectroscopy was applied to analyse the distribution and concentration of biomolecules of atherosclerotic plaques of mice supplemented with egg-rich diet and with or without perindopril treatment. The synchrotron radiation used as a source allowed precise point analysis as well as 2D imaging with a spatial resolution of $12 \mu \mathrm{m}$ of the tested samples. The increase of lipids saturation (after diet supplementation) may indicate the role of lipid oxidation in the progress of atherosclerosis, followed by the oxidation stress. The change in amide band ratios implies the 
changes in protein secondary structure. The analysis of calcium minerals hold out the content of atherosclerotic lesions.

\section{Acknowledgments}

The research leading to these results has received funding from the European Community's Seventh Framework Programme (FP7/2007-2013) under grant agreement no. 226716 .

\section{References}

[1] G K. Hansson, N. Engl. J. Med. 352, 1686 (2005).

[2] M. Franczyk-Żarów, K.B. Kostogrys, B. Szymczyk, J. Jawień, M. Gajda, T. Cichocki, L. Wojnar, S. Chłopicki, P.M. Pisulewski, Br. J. Nutr. 99, 49 (2008).

[3] J. Jawien, G. Csanyi, M. Gajda, L. Mateuszuk, M. Lomnicka, R. Korbut, S. Chłopicki, Eur. J. Pharmacol. 556, 129 (2007).

[4] M. Gajda, K. Banas, A. Banas, J. Jawien, L. Mateuszuk, S. Chłopicki, W.M. Kwiatek, T. Cichocki, G. Falkenberg, X-ray Spectrom. 37, 495 (2008).

[5] D.J. McNamara, Biochim. Biophys. Acta 1529, 310 (2000).

[6] U.P. Steinbrecher, S. Parthasarathy, D.S. Leake, J.L. Witztum, D. Steinberg, Proc. Natl. Acad. Sci. USA 81, 3883 (1984).

[7] K.L.H. Carpenter, S.E. Taylor, J.A. Ballantine, B. Fussell, B. Halliwell, M.J. Mitchinson, Biochim. Biophys. Acta 1167, 121 (1993).

[8] J. Constant, Keio J. Med. 53, 131 (2004).
[9] R. Candido, K.A. Jandeleit-Dahm, Z. Cao, S.P. Nesteroff, W.C. Burns, S.M. Twigg, R.J. Dilley, M.E. Cooper, T.J. Allen, Circulation 106, 246 (2002).

[10] C. Ceconi, K.M. Fox, W.J. Remme, M.L. Simoons, J.W. Deckers, M. Bertrand, G. Parrinello, C. Kluft, A. Blann, D. Cokkinos, R. Ferrari, Atherosclerosis 204, 273 (2009).

[11] M. Gajda, J. Kowalska, A. Banaś, K. Banaś, W.M. Kwiatek, R.B. Kostogrys, Ł. Mateuszuk, S. Chłopicki, J.A. Litwin, K. Appel, Rad. Phys. Chem. 80, 1072 (2011).

[12] D. McNaughton, B.R. Wood, Aust. J. Chem., http://dx.doi.org/10.1071/CH11365 .

[13] C. Petibois, Anal. Bioanal. Chem. 397, 2031 (2010).

[14] P. Bassan, A. Kohler, H. Martens, J. Lee, H.J. Byrne, P. Dumas, E. Gazi, M. Brown, N. Clarke, P. Gardner, Analyst 135, 268 (2010)

[15] G. Socrates, Infrared and Raman Characteristic Group Frequencies: Tables and Charts, Wiley, Chichester 2004.

[16] M.C. Hull, L.R. Cambrea, J.S. Hovis, Anal. Chem. 77, 6069 (2005).

[17] L.K. Tamm, A. Suren, Q. Rev. Biophys. 30, 365 (1997).

[18] H. Martens, T. Naes, Multivariate Calibration, Wiley, New York 1994.

[19] L.L. Demer, K.E. Watson, K. Boström, Trends Cardiovas. Med. 4, 45 (2004).

[20] L.L. Demer, A.P. Sage, Y. Tintut, Arterioscl. Throm. Vas. Biol. 28, 1882 (2008).

[21] S.J. Onufrak, A. Bellasi, L.J. Shaw, C.A. Herzog, F. Cardarelli, P.W. Wilson, V. Vaccarino, P. Raggi, Atherosclerosis 199, 424 (2008). 